\title{
Psicose infantil: revisão de literatura a partir da psicanálise lacaniana
}

\author{
Child psychosis: literature review from the Lacanian psychoanalysis
}

Sara Mexko ${ }^{[a]}$, Cristiano Machado Galhardi[b]

\footnotetext{
${ }^{[a]}$ Especialista em Saúde Mental e Atenção Psicossocial pelo Instituto de Ensino, Capacitação e Pós-Graduação - Faculdade Iguaçú, Assis, SP - Brasil, e-mail: saramexko@hotmail.com

${ }^{[b]}$ Doutor em Fisiopatologia em Clínica Médica (Ciências da Saúde), professor do Instituto de Ensino, Capacitação e Pós-Graduação - Faculdade Iguaçú, Assis, SP - Brasil, e-mail: cmgalhardi@gmail.com
}

Recebido: $19 / 07 / 2012$ Received: 07/19/2012

Aprovado: 28/11/2012 Approved: 11/28/2012

\section{Resumo}

Este artigo aborda a temática das psicoses infantis. Para tanto, parte da compreensão de como se dá a estruturação subjetiva da criança a partir do referencial da psicanálise lacaniana. Como forma de nortear o trabalho, foram usadas algumas questões que serviram como balizas na construção do texto. Como se dá a estruturação subjetiva da criança? O que se passa na estruturação subjetiva da criança que se torna psicótica? Buscou-se, por meio de revisão bibliográfica sobre o tema, responder a estes questionamentos. Constatou-se que, a estruturação subjetiva da criança se dá a partir do campo do Outro. A criança precisa adentrar a operação de alienação, ocupar o lugar de objeto de desejo do Outro, por um tempo. Necessita também se separar deste Outro e, para tal, vale-se da metáfora paterna. Na estruturação psicótica, há uma foraclusão do significante Nome-do-Pai (S2) e a criança permanece presa ao significante primordial Desejo da mãe (S1), não conseguindo se separar psiquicamente do Outro. Desta forma, não acessa o mundo simbólico e não se constitui como sujeito desejante.

Palavras-chave: Psicose. Psicanálise. Alienação. Separação.

\section{Abstract}

This article discusses the theme of childhood psychoses. To this end, aims to understand how the child's subjective structuring based on the Lacanian psychoanalysis referential. As a way to guide the work, we approached some issues that have served as the basis for the construction of the text. How does the child's subjective structuring is created? What happens in the subjective structuring of a child that becomes psychotic? Through a literature review on the topic, we tried to answer these questions. It was found that the subjective structuring of the child is related to the field of the Other. The child must get into the alienation operation, take the place of the object of desire of the Other for a while. And also needs to separate from this Other, and to this end, uses the paternal metaphor. In the psychotic structuring, there is a foreclosure of the signifier Nameof-the-father (S2), and the child remains attached to the primordial Desire of the mother signifier (S1), failing to psychically separate from the Other. Thus, he/she does not have access to the symbolic world and does not constitute himself/herself as a desiring subject.

Keywords: Psychosis. Psychoanalysis. Alienation. Separation. 


\section{Introduç̃̃o}

Busca-se ao longo do texto, abordar a psicose infantil a partir de um viés não organicista, diferentemente do que muitos psiquiatras e neurologistas propõem. A psicanálise aponta uma possibilidade de compreensão da psicose, pensado-a como uma das possibilidades de constituição da subjetividade humana. Para trazer luz à questão, é realizado um percurso pelo processo de constituição subjetiva, essencialmente em relação à estruturação psicótica.

Os seres humanos se constituem a partir do encontro entre dois campos bastante heterogêneos. De um lado, o aparelho biológico dotado de potencialidades, constituído especialmente pelo sistema nervoso; e de outro, o campo simbólico, estruturado por meio da linguagem. Para que ocorra o nascimento de um sujeito psíquico é indispensável o encontro entre o organismo biológico e uma estrutura familiar que irá fazer a transmissão do sistema simbólico (Bernardino, 2006).

A psicanálise lacaniana trabalha com o conceito de estrutura. Lacan desenvolve este conceito em psicanálise, articulando os três registros: real, imaginário e simbólico. Para o autor (Lacan, 1990, p. 193), "[...] o inconsciente é estruturado como uma linguagem". O sujeito não se desenvolve, o que se desenvolve é o corpo. 0 sujeito se estrutura, e isto se dá a partir do campo do Outro.

A estrutura da linguagem é anterior ao nascimento do sujeito. Segundo Vorcaro (1999, p. 20), "o Sujeito é o efeito da divisão própria ao funcionamento da linguagem, portanto, não pré-existe a ela". O campo do Outro é onde está situada a linguagem, e o Outro é o "[...] lugar em que se situa a cadeia do significante que comanda tudo que vai poder presentificar-se do sujeito, é o campo desse vivo onde o sujeito tem que aparecer" (Lacan, 1990a, p. 193-194).

Apenas após o movimento inicial em direção ao Outro que o sujeito pode começar a se tornar algo, se subjetivar. Este primeiro momento da criança em direção ao Outro consiste na primeira operação essencial de causação do sujeito, a Alienação. Esta inaugura a inscrição do significante primordial (S1), ser o objeto de desejo da mãe. Para ilustrar esta primeira operação Lacan faz uso da forma da reunião dentro da lógica matemática dos conjuntos. Os aspectos enfatizados por Lacan são descritos por Fernandes:
"[...] tanto a impossibilidade da existência do sujeito, senão em sua reunião ao Outro, quanto a perda que se dá nesta mesma operação, tendo em vista que o sujeito não se esgota, não se representa por inteiro no Outro, perdendo, na operação de alienação, parte de seu ser" (2000, p 57).

A segunda operação essencial ao nascimento do sujeito é a Separação. A forma dentro da lógica matemática dos conjuntos que representa este segundo tempo da constituição subjetiva é a interseção. Na Separação há uma substituição de significantes, o S1 é substituído pelo significante Nome-do-Pai (S2). De acordo com Dor (1991), com a introdução desse novo significante (S2), o qual substitui o significante S1, este último passa ao inconsciente (p. 53). A partir da introdução do significante Nome-do-Pai, a criança poderá se separar psiquicamente da mãe, se constituindo como sujeito desejante.

As operações de Alienação e Separação são fundantes do Sujeito. Para compreender um pouco de como se dá o aparecimento do sujeito desejante, faz-se necessário adentrar um pouco mais na relação da criança com o Outro.

\section{A constituição subjetiva da criança}

O Outro Primordial possui uma ilusão antecipadora que possibilita ver no bebê aquilo que ele ainda não é. Esta suposição sustentada pelo agente materno é imprescindível para que o bebê possa tornar-se um sujeito (Laznik, 2005). Mas para que esta antecipação possa se dar, para que a mãe possa proporcionar ao seu bebê mais do que os cuidados necessários à sua sobrevivência, é imperioso que ela tenha desejado o filho. Este desejo está para além do desejo de ficar grávida, de transmitir sua carga genética, de educar uma criança, de formar uma família, ele vem como uma tentativa de obturar uma falta de ordem estrutural. Falta que a mãe por um tempo supõe que pode ser preenchida por um filho, o qual comparece como causa de desejo da mãe.

Para que o bebê possa ocupar o lugar do que falta à mãe, "[...] é necessário que exista na mãe uma falta de tal natureza que só o filho preencha, sendo necessário seu desejo para que o bebê se transforme em sujeito" (Licht, p. 69, citado por Bernardino, 2006). Se não houver a marca desta falta na mãe, a facilização do bebê não será possível. 
Quando a mãe é faltante, o bebê se faz suporte do desejo, respondendo a um desejo estrutural dela. Fourment-Aptekman retomou Lacan para dizer que: "[...] para o bebê, alguma coisa falta, há um lugar vazio, e a criança preenche esse vazio identificando-se imaginariamente com o objeto que se supõe faltar à mãe, isto é, o falo" (2006, p. 115, citado por Bernardino). 0 falo ${ }^{1}$ é o significante de uma falta. Ao se fazer objeto de desejo do Outro materno, o bebê está determinado pelo significante primordial (S1), que é ser o objeto de desejo da mãe.

Ao se fazer objeto de desejo da mãe, o bebê adentra a operação de Alienação, que é imprescindível para a constituição de um ser falante. Bernardino afirmou que, para que uma criança possua existência simbólica, é necessário que ela se aliene no desejo e nas palavras de outro humano (Bernardino, 2006a).

Forma-se então uma união narcisista, uma célula narcísica mãe-bebê, cujo acesso é bastante difícil. Por um tempo, e isto é necessário que aconteça, o bebê irá ocupar o lugar e a função designada pela mãe, identificado imaginariamente com o falo. De acordo com Dor (1991, p. 47), a criança, "[...] neste limiar do Édipo, mantém uma relação com a falo aparentemente estranha à castração, já que ela é, ela própria, o objeto fálico".

Neste primeiro tempo do Édipo, a criança deseja ser tudo para a mãe, transformando-se naquilo que a mãe deseja. Bleichmar (1984) caracterizou o desejo da criança, apontando que é sempre desejo do outro. E este desejo tem duplo sentido, é tanto desejo de ser desejado pelo outro, como também uma tomada do desejo do outro como se fosse seu próprio desejo.

Ainda que no primeiro tempo exista uma célula narcísica mãe-filho, esta relação está mediada por um terceiro, o falo, que representa a falta na mãe. Embora seja assinalado como uma díade, o laço da mãe com o bebê nunca é dual, já que "[...] não há complementariedade possível - a não ser a que é imaginada miticamente - pois o laço mãe-bebê sempre comporta pelo menos três termos estabelecidos

\footnotetext{
1 "Na teoria lacaniana, a palavra falo não designa o órgão genital masculino. É um nome de um significante muito particular, diferente de todos os outros significantes, que tem por função significar tudo o que depende de perto ou de longe, da dimensão sexual" (Nasio, 1993, p. 31).
}

pela estrutura: mãe - falo - bebê" (Laznik, 2005, p. 265).

Não sendo possível a complementariedade, visto que a falta da mãe é de ordem estrutural, possui relação com seu Édipo, o bebê logo irá pressentir. Até que o bebê se dê conta da impossibilidade de ser o único objeto de desejo da mãe, esta ilusão de ser o falo da mãe o acompanhará por um tempo. Esta ilusão também acompanha a mãe, e está presente desde o nascimento do bebê.

A mãe, na função de Outro Primordial, irá cuidar do bebê, investindo libidinalmente nele. Enquanto promove os cuidados para a manutenção da vida da criança, como alimentá-la, esquentá-la, também oferece seus sentimentos. Esta mãe supõe, desde os primeiros dias do bebê, que ele é um sujeito.

Ainda nos primeiros dias de vida do bebê, quando as produções dele têm como base reações neurológicas involuntárias, a mãe atribui a ele a autoria de certas produções, sustentando uma posição ativa do filho (Laznik, 2005).

Trata-se de um engodo, um engano, no entanto, é uma operação constituinte do sujeito, que precisa ser sustentada pelos agentes materno e paterno. Fernandes (2000) destacou que o engano estruturante consiste na capacidade do Outro materno enganar-se com o bebê, metaforizando-o, sem, no entanto, perder a dimensão real do infans.

Diante do choro do bebê, a mãe supõe que este lhe dirige uma demanda, que pode ser interpretada como sendo de alimento, de banho, de colo. Ela procura responder a este choro, providenciando o cuidado, acreditando que a pequena criança lhe endereçou um pedido. Entretanto, quem realiza a demanda é a mãe. Demanda que o bebê tome seu leite, que ele tome banho, que ele fique em seu colo, que durma, entre outras. Fernandes (2000, p. 65) escreve que: "Trata-se, portanto, no Outro primordial, de um Outro que demanda, que projeta no pequeno ser em sua frente - em seus gritos e esperneios - suas próprias demandas".

Enquanto provê os cuidados ao bebê, a partir do que supõe que ele lhe demanda, a mãe nomeia à criança aquilo que a afeta, assim, o bebê vai aos poucos sendo introduzido na linguagem. Mas esta introdução da criança na linguagem pressupõe que existam outros elementos, não somente a mãe e a criança, mas também o pai enquanto quem possibilita a palavra. 
J. Jerusalinsky (2002) argumenta que existem dois momentos da operação constituinte denominada estabelecimento da demanda. No primeiro momento, descrito anteriormente, é a mãe que demanda do bebê, requerendo que ele demande dela. Enquanto que, no segundo momento, quando já estão inscritos os efeitos desta operação constituinte, o bebê começa efetivamente a demandar.

Nos cuidados com o bebê, ao atender suas demandas, o agente materno nem sempre responde da mesma forma. Em alguns momentos a criança chora e a mãe em instantes vai atendê-lo, em outros instantes a criança chora e a mãe demora um tempo um pouco maior para atendê-la. Há uma alternância neste cuidado, que imprime o ritmo das funções orgânicas do bebê. Neste sentido, J. Jerusalinsky (2002) postulou que:

É a alternância simbólica entre presença e ausência que permitirá, juntamente com a ação específica, a inscrição pulsional do bebê, que abandona então o puro funcionamento da necessidade e passa a construir um funcionamento no qual a obtenção de prazer fica atrelada à série de presença-ausência e aos ritmos de alternância que o Outro lhe propôs (p. 251).

Mas não é possível estabelecer a alternância sem que anteriormente a mãe tenha se estabelecido enquanto presença para o bebê. Também não ocorrerá a inscrição pulsional se o Outro Primordial se colocar apenas como presença, ou somente como ausência. A alternância entre presença e ausência consiste em uma operação simbólica, a qual permitirá a inscrição pulsional (Teperman, citado por Sales, 2005; J. Jerusalinsky, 2002).

Esta alternância entre os momentos de presença e de ausência do Outro Primordial, entre as idas e vindas da mãe, do cuidado e da espera do cuidado, possibilitam que a criança ao poucos se dê conta que ela não é tudo para sua mãe, que outros objetos convocam o desejo da mãe.

A partir do investimento da mãe em outros objetos é criado um espaço onde o sujeito nascente constituirá em si a ideia de possuir um corpo próprio e integrado (Sales, 2005). Para que a mãe invista em outros objetos que não a criança, é imprescindível que ela deseje separar-se do filho, reintegrando-se a sua condição de faltante. Isto só é possível porque ela também passou pelo complexo de Édipo e se estruturou enquanto castrada, portanto, faltante.

Em decorrência da repetição das ausências da mãe, sentidas pelo bebê, ele formula uma hipótese: de que há outro objeto para o qual a mãe lança seu olhar desejante, e do qual supõe ser capaz de satisfazer seu desejo. A partir desta constatação por parte da criança, fica imposta para ela a falta estrutural na mãe e, como corolário, a impossibilidade de continuar a ser o falo da mãe. Fernandes (2000) descreveu o acontecimento:

Confrontada, entretanto, com a falta inerente ao desejo materno - momento preconizado pela intervenção do pai, tal crença desemboca na experiência de castração desta ilusão, remetendo tanto o menino quanto a menina a consentir com uma falta fundamental e engajar-se em sua sexuação (p. 125).

É realizada uma associação, por parte da criança, entre as ausências da mãe com a presença do pai. Este homem, representante da função paterna passa a ser visto pela criança como quem tem aquilo que supostamente a mãe deseja. Escrevendo sobre o Pai real, Dor (1991) apontou que:

A consistência do Pai real quanto ao desejo da mãe vai, então, começar a questionar a economia do desejo do filho sob esta forma de intrusão. Essa interpelação suscita nele, assim, um requestionamento de sua identificação imaginária com o objeto de desejo da mãe. A criança entra, a partir daí, num momento de incerteza psíquica quanto à questão de seu desejo relativamente à certeza que antes tinha dele diante do desejo da mãe (p. 47).

A entrada deste terceiro, operando como função paterna, realiza um corte na célula narcísica mãe-bebê, operando a castração, o que possibilita que a criança possa advir como sujeito. Como isso ocorre? Enquanto representante da Função Paterna, o pai realiza a interdição do primeiro objeto de satisfação que a criança possui - a mãe. Trata-se do fundamento do complexo de Édipo. A fim de que a criança não permaneça sempre tendo que se fazer de objeto da mãe, é imprescindível que o desejo materno seja interditado.

Cabe ao pai ser representante simbólico da lei primordial da proibição do incesto. "A função paterna não opera por imagens, opera por meio da 
palavra que transmite a lei, lei de proibição do incesto, portanto simbólica" (Viviani, 2003). Em algumas situações, quando a criança se encontra muito expansiva, o pai precisa manifestá-la de forma direta. Todavia seu papel se situa para além disto; ele quem sustenta a lei, por meio de sua presença, produzindo efeitos no inconsciente materno.

0 pai priva a mãe de seu objeto fálico, no caso, a criança. A mãe não mais poderá permanecer colada a criança, pois um outro se apresenta como detentor de seu desejo. Dor (1991) destaca que não se faz necessário que o pai se mostre em todos os momentos como um privador, visto que, apenas a incerteza que se produz na criança em ser o objeto de desejo da mãe, propicia que aquela fique mais sensível à presença do pai.

Quanto à criança, esta é frustrada em ser o objeto fálico da mãe. Assim, por mais que a criança se ofereça à mãe na tentativa de voltar a ser o objeto que satisfaz seu desejo, diante da percepção da impossibilidade em ser tal objeto, ela se confrontará com a falta $(-\varphi)$. 0 pai então passa a ser representado como um pai frustrador, como propõe Joel Dor (1991, p. 48): “A privação unida ao interdito só pode, enfim, suscitar na criança a representação de um pai frustrador, que lhe impõe ser confrontado com a falta imaginária desse objeto real que é a mãe e da qual ela necessita".

De forma geral, a criança percebe o pai como um objeto rival, concorrendo com ela em ser o objeto de desejo da mãe. Aos olhos da criança, o pai surge hipoteticamente como um falo rival. Por meio desta rivalidade, a criança irá deparar com a constatação de que a mãe é dependente do desejo do pai. A partir deste acontecimento, a criança entra "[...] num momento de incerteza psíquica quanto à questão de seu desejo relativamente à certeza que antes tinha dele diante do desejo da mãe" (Dor, 1991, p. 46).

Bleichmar (1984) salienta que não é necessário existir a presença física de um homem para que a criança pressinta não ser o objeto fálico da mãe. A mãe pode desejar outros objetos, não apenas seu filho. Este desejo pode estar relacionado a uma profissão, a uma atividade que ela faz com satisfação, e até mesmo na imaginação em ter outro homem como seu companheiro.

Se a mãe reconhece existir uma lei acima de sua vontade, isto é, que ela própria está submetida a esta lei, isso possibilita que ocorra a castração simbólica. Nesta acepção é possível concluir que:
Todo terceiro que responder a esta função mediatizando os desejos respectivos da mãe e do filho vai instituir, por sua incidência, o alcance legalizador da interdição do incesto. Ora, responder a esta função implica unicamente que seja convocado, em posição de referente terceiro, o significante do Pai simbólico, isto é, o significante fálico enquanto simbolizando o objeto da falta desejado pela mãe. Desse ponto de vista, esta função mediatizante não exige de forma alguma, em última instância, a existência hic et nunc de um Pai real, em outras palavras, de um homem (Dor, 1.991, p. 42).

Perante esta colocação, torna-se imperiosa a necessidade de pensar o papel da mãe, perante o desejo da criança em permanecer colada a ela. A mãe precisa significar ao seu bebê que se encontra submetida à lei paterna, reconhecendo também "[...] a lei do pai como aquela que mediatiza seu próprio desejo" (Dor, 1991, p. 49). Para que a alterização possa se instalar, é preciso que exista a lei paterna na mãe. Além disto, a mãe necessita testemunhar à criança que não espera obter dela aquela coisa que julga lhe faltar, mas de um homem, no caso, do pai.

0 representante da função paterna adiciona uma assimetria na relação mãe-bebê, barrando o desejo da mãe, de tal modo que a criança não seja devorada pelo desejo materno. Dias (citado Kupfer, Teperman, 2008, p. 80) explanou que "A lei dita que a criança não é tudo para a mãe franqueando sua subtração, descolamento, da imediatez do mundo das coisas e autorizando-a à capacidade de substituição significante, o mundo das palavras".

É em nome deste terceiro, representante da função paterna, que a criança poderá abandonar a condição de objeto de desejo materno, para poder surgir como um sujeito separado dela. Tem-se então a castração, que é aceita pela criança em nome do pai. Esta operação de castração assinala a falta de completude da criança.

Hélio Pellegrino (1988) comentou que o ser humano passa por dois nascimentos. 0 primeiro deles é quando saímos do útero materno, amplamente conhecido por todos. Já o segundo nascimento se dá "[...] pela Lei do Pai, que interdita o incesto e instaura o primado da linguagem e da ordem do simbólico [...]" (p. 100).

A mãe precisa realizar uma mudança de posição subjetiva, deixando um pouco a posição de mãe, para começar ocupar a posição de mulher. Com esta 
mudança de posição subjetiva, a criança não pode mais ocupar o lugar de falo, tornando clara a falta estrutural na mãe. Por parte da criança há a necessidade de se fazer uma renúncia, deixando de ser o único objeto que ilusoriamente completa a mãe.

0 corte realizado pelo pai é imprescindível, visto que, trata-se da condição para que a criança não fique condenada a ter que responder todo o tempo ao desejo da mãe. Abandonando a impossível tarefa de satisfazer a mãe, a criança poderá trilhar seu próprio caminho, fazer suas escolhas, desejar outros objetos, enfim, colocar-se como sujeito. Dor (1991) conjeturou sobre esta mudança:

A renúncia da criança ao objeto fundamental de seu desejo, se é, antes de mais nada, uma renuncia simbólica, não é no entanto derrisória. Abrindo para ela, propriamente falando, o acesso ao simbólico, essa renúncia lhe assegura a possibilidade de poder se manifestar aí, ela mesma, como sujeito, a partir do momento em que é ela quem designa (p. 54).

Neste terceiro tempo do Édipo, dada a castração simbólica, a criança deixa de ser o objeto que obtura a falta na mãe, ou seja, o falo. 0 pai também não é referido como sendo o falo. A mãe passa a não ser mais a lei, e o pai também não o é. 0 falo passa a ser um atributo que se tem ou não tem. No que tange à lei, esta "[...] passa a ser uma instância em cuja representação um personagem possa agir, mas não o será" (Bleichmar, 1984, p. 57).

Através da operação inaugural designada como metáfora paterna e do mecanismo de recalque originário, se produzirá uma divisão no sujeito e a criança irá se constituir enquanto sujeito de desejo, sendo lançada ao fala-ser. 0 significante originário Desejo da mãe é recalcado tornando-se inconsciente, e é substituído pelo significante Nome-do-Pai. Na subjetividade da criança, quando o desejo da mãe é substituído pelo Nome-do-Pai, passa a existir a significação fálica (Bleichmar, 1984).

A criança, sujeito de desejo, buscará outros objetos os quais ela acredita que possam lhe satisfazer, pois agora ela também é portadora de uma falta estrutural. Por meio da substituição de significantes, a criança poderá continuar a designar, sem se dar conta, seu desejo primordial pelo Outro materno, desejo que permanece recalcado.

A partir da substituição de significantes, a criança se encontrará em uma posição diferente; ocorre uma divisão subjetiva na criança, ficando uma parte de si inconsciente. Se este processo ocorrer como esperado, funda-se um sujeito dividido, de estrutura neurótica, portando uma falta estrutural, logo desejante, e atravessado pela linguagem. Dor (1991, p. 53) assinalou que: "[...] o símbolo da linguagem tem por função principal perpetuar o objeto originário do desejo numa designação, sem que o sujeito daí por diante saiba alguma coisa sobre isso".

\section{A estruturação subjetiva na psicose}

A estruturação psicótica possui diferença da estruturação neurótica. Nesta última, o sujeito passa pelos três tempos do complexo de Édipo, sai da relação de complementaridade com a mãe, recalca o significante Desejo da mãe e ascende à linguagem. Para Vorcaro (1999, p. 69), "a criança se constituirá sujeito neurótico nessa relação com alguém que sabe enfrentar e solucionar o perigo desse abismo de tornar-se presa do Outro".

Uma criança que poderá se estruturar psicótica se faz objeto de desejo da mãe, se oferece a ela. A operação de Alienação se deu, ela se põe como falo materno. Todavia, a mãe não consegue se privar desse gozo, e continua a demandar dela indefinidamente. Se a mãe não abre espaço para a função paterna, não alimenta a interdição simbólica, não haverá espaço para que a alterização se instale, ficando a criança condenada à "[...] posição de objeto do gozo materno" (Jerusalinsky, 2002, p. 163).

Não se apressando em culpar a mãe, Jerusalinsky (1984) destaca que, não se deve procurar a falha na mãe, mas no que, no desejo materno, fecha a possibilidade de que o significante Nome-do-Pai ocupe seu lugar.

Laznik (2005) considerou que, na psicose infantil, acontece o fracasso da função separadora produzida pela metáfora paterna. Esta função estaria foracluída. A falha na inserção da função paterna incide em uma falha no recalque originário. 0 significante Nome-do-Pai (S2) não é inscrito na subjetividade da criança, isto é, fica foracluído, ficando externo ao universo simbólico, o que gera um fracasso no processo de separação.

Não havendo a substituição do significante desejo da mãe pelo significante Nome-do-Pai, como consequência a criança não ultrapassa a relação dual com a mãe, só lhe restando seguir colada ao significante 
primordial desejo da mãe. Permanecendo atrelada a este significante primordial, a criança não terá condições simbólicas de significar sua existência.

A ausência do significante Nome-do-Pai (S2) provoca um furo no campo das significações (Kupfer, 2001). Como não há a inscrição do significante Nome-do-Pai, o psicótico não poderá nomear com outros significantes o seu desejo pelo Outro primordial. Não sendo possível um deslizamento de significantes, não há como haver um sentido na cadeia significante, já que faltam os articuladores desta cadeia.

Como não possui condições de nomear simbolicamente sua existência, encontra dificuldades em viver em um mundo governado por leis que balizam os laços sociais. 0 infans fica alienado pela lei do desejo materno, como propuseram Vanoli e Bernardino (2001): "Na psicose infantil está em jogo uma palavra absoluta que oferece à criança um sentido único. A criança psicótica não consegue simbolizar, não faz metáfora, permanecendo numa posição de alienação, prisioneira de uma palavra que é lei".

Sem separar-se psiquicamente da mãe, a criança não terá como "[...] advir como sujeito de desejo" (Jerusalinsky, 2002, p. 163). Não abre a possibilidade de internalizar as leis que fornecem referenciais e possibilitam a relação com terceiros, como pai, avós, amigos, professores e outros. Fica presa a sempre ter que responder ao desejo do Outro, sem ter condições de constituir seus próprios desejos.

Na psicose infantil, o Outro é absoluto, fornecendo à criança uma palavra absoluta. Esta palavra, de sentido único, tira da linguagem a sua flexibilidade, as múltiplas possibilidades de sentido (Kupfer, 2001). Lembrando que a psicose na criança não se dá da mesma maneira que no adulto. Se no adulto observa-se principalmente o delírio e a alucinação, na criança notam-se as estereotipias motoras aparentemente sem sentido, a construção de novas palavras que só adquirem sentido em sua história, além da incapacidade de brincar de faz de conta.

\section{Considerações finais}

As pesquisas empíricas e estudos teóricos sobre a psicose infantil são de grande validade para os profissionais da área da saúde e escolar, especialmente os que trabalham com crianças psicóticas. A compreensão sobre a etiologia e a psicodinâmica da psicose infantil pode facilitar o trabalho com estas crianças.

Diversas áreas da ciência tem se debruçado sobre a temática da psicose, cada uma tentando dar algum tipo de explicação a partir de sua perspectiva. A psicanálise propõe a compreensão da psicose a partir das estruturas clínicas, sendo a psicose uma forma de estruturação subjetiva.

Sendo a psicose infantil uma das possibilidades de estruturação subjetiva da criança, não é necessário alocá-la a uma doença. Trata-se apenas de uma estruturação diferente da maioria da população, que é neurótica. Em se tratando de crianças, o futuro ainda não se encontra decidido, visto que o processo de estruturação subjetiva está em curso.

Ainda que uma criança esteja em processo de estruturação psíquica psicótica, não deve ser dada como algo acabado. Um trabalho com esta criança e com os representantes da função materna e paterna, pautado na ética psicanalítica, permite que possam ocorrer novas inscrições e reinscrições na criança, o que abre espaço para a estruturação do sujeito desejante (Jerusalinsky, 2002). Mas é preciso que este trabalho se inicie ao menos até a adolescência, enquanto a estrutura ainda não se encontra decidida.

\section{Referências}

Bernardino, L. M. F. (2006). A abordagem psicanalítica do desenvolvimento infantil e suas vicissitudes. In Bernardino (Org.). O que a psicanálise pode ensinar sobre a criança, sujeito em constituição. (pp. 19-41). São Paulo: Escuta.

Bleichmar, H. (1984). Introdução ao estudo das perversões: a teoria do Édipo em Freud e Lacan. (E. O. Dielh, Trad). Porto Alegre: Artes Médicas.

Dias, M. M. (2008). Progressos da ciência, destinos do sujeito. In M. C. M. Kufper \&, D. Teperman (Org.). $O$ que os bebês provocam nos psicanalistas. (pp. 71-84). São Paulo: Escuta.

Dor, J. (1991). 0 pai e sua função em psicanálise. (D. D. Estrada, Trad.). Rio de Janeiro: Zahar.

Fernandes, L. R. (2000). O olhar do engano: Autismo e o Outro Primordial. São Paulo: Escuta. 
Fourment-Aptekman, M. C. Resistências à psicanálise do bebê: contribuição da psicologia do desenvolvimento. In L. M. F. Bernardino (Org.). O que a psicanálise pode ensinar sobre a criança, sujeito em constituição. (pp. 107-117). São Paulo: Escuta.

Jerusalinsky, N. A. (1984). Psicanálise do Autismo. Artes Médicas.

Jerusalinsky, J. (2002). Enquanto a futuro não vem: a Psicanálise na clínica interdisciplinar com bebês. Salvador: Ágalma.

Kupfer, M. C. (2001). Educação para o futuro: Psicanálise e educação. (2. ed). São Paulo: Escuta.

Lacan, J. (1990). Os quatro conceitos fundamentais da psicanálise. In J. Lacan. O seminário - livro 11. (J. A. Miller, Trad.). Rio de Janeiro: Jorge Zahar.

Laznik, M. C. (2005). A voz da sereia: o autismo e os impasses na constituição do sujeito. Salvador: Ágalma.

Licht, R. W. (2006). Na sala de espera esperando o Outro: uma interlocução entre as pesquisas neurológicas e a psicanálise. In L. M. F. Bernardino (org). o que a psicanálise pode ensinar sobre a criança, sujeito em constituição. (pp. 67-80). São Paulo: Escuta.
Nasio, J. D. (1993). Cinco lições sobre a teoria de Jacques Lacan. (V. Ribeiro, Trad.). Rio de Janeiro: Jorge Zahar.

Pellegrino, H. (1998). A burrice do demônio. Rio de Janeiro: Rocco.

Sales, L. (2005). Preocupações acerca dos efeitos psíquicos do aleitamento materno exclusive sobre a função materna e sobre o bebê. In L. Sales (Org.). Pra que essa boca tão grande? - Questões acerca da oralidade. (pp. 115-132). Salvador: Ágalma.

Teperman, D. (2005). Psicopatologia da alimentação cotidiana. In L. Sales (Org). Pra que essa boca tão grande? - Questões acerca da oralidade. (pp. 189-198). Salvador: Ágalma.

Vanoli, E. N., \& Bernardino, L. F. (2008). Psicose infantil: uma reflexão sobre a relevância da intervenção psicanalítica. Estilos da clínica, São Paulo, 13(25). Recuperado em 02 maio 2011, de http:// www.revistasusp.sibi.usp.br/scielo.php?script=sci_ arttext\&pid=S1415-71282008000200015\&lng=pt\& nrm=isoViviani, M. L. S. (2003). Sobre a função paterna. In A. M. MEIRA (Org.). Novos sintomas. (F. F. Settineri, Trad.)(pp. 55-63). Salvador: Ágalma.

Vorcaro, A. M. R. (1999). Crianças na psicanálise: clínica, instituição, laço social. Rio de Janeiro: Companhia de Freud. 